\title{
Juventude e transitoriedade: o perfil dos residentes do IRPAA e os aspectos de sua formação
}

\author{
Alexandre Junior de Souza Menezes ${ }^{1}$ \\ Ricardo Jose Rocha Amorim² \\ Adelson Dias de Oliveira ${ }^{3}$
}

\begin{abstract}
Resumo:
O presente artigo tem como objetivo ampliar a especificidade da abordagem histórica que gira em torno da discussão "repúblicas estudantis" e "juventude", bem como desenvolver considerações teórico/metodológicas sobre a condição juvenil vivida por estes jovens. Utiliza-se metodologicamente de narrativas de 10 (dez) colaboradores, sendo 6 (seis) jovens que vivem e 4 (quatro) que viveram em uma república de estudantes mantida por uma organização não governamental situada na cidade de Juazeiro, na Bahia, em que oferecem para além da estadia possibilidades formativas no âmbito da convivência com o semiárido, aspecto este que se contrapõe a formação técnica profissionalizante sob os quais estão submetidos. Apresenta como principais resultados a reflexão de que estes jovens que são de origens diferentes, seja do campo com bases tradicionais (indígenas, quilombolas, pescadores, agricultores familiares, familiares, fundo de pasto, movimentos sociais, etc.), se constituem como jovens transitórios, sendo o resultado do processo de construção do sujeito, a partir do hibridismo juvenil, influenciado pelos movimentos transitórios, o que configura como principal desafio para se pensar e propor processos formativos que atendam às necessidades específicas destes sujeitos, seja no campo educacional, de movimentos sociais e/ou da ecologia humana.
\end{abstract}

\section{Palavras-chave:}

Formação. Hibridismo juvenil. Movimento transitório. Narrativas.

\section{Youth and transience: the profile of IRPAA residents and aspects of their formation}

Abstract: The present article aims to widen the specificity of the historical approach that revolves around the issue "student residences" and "youth" as well as to develop theoretical/methodological considerations about the youth condition experienced by these young people. This study methodologically employed the narratives of 10 (ten) subjects, 6 (six) of which live and 4 (four) of which lived

\footnotetext{
1 Doutorando em Agroecologia e Desenvolvimento Territorial. E-mail: alexandrejuniorsm@hotmail.com. ORCID iD: https://orcid.org/0000-0002-7420-8387.

2 Doutor em Electrónica y Computación, Professor da UNEB. E-mail: amorim.ricardo@gmail.com. ORCID iD: https://orcid.org/ 0000-0001-9527-2751.

3 Doutor em Educação, professor da Univasf. E-mail: adelsonjovem@gmail.com. ORCID iD: https://orcid.org/0000-0001-8415-1153.
} 
in a student residence supported by a non-governmental organization located in Juazeiro, Bahia, which, in addition to housing, offers formation possibilities in the context of the coexistence with the semi-arid, an aspect that opposes the professional technical training to which they are subjected. This study presents as its main result the reflection that these young people have different origins, especially from the field, with traditional backgrounds (indigenous, quilombo, fishers, family farmers, fundo de pasto communities, social movements, etc.), constituting transitory young people, with the result of the process of construction of the subject, from the young hybridism perspective, being influenced by transitory movements, constituting the main challenge in order to think and propose formative processes that meet the specific needs of these individuals in the educational field, in the social movements, and/or human ecology.

Keywords: Formation. Young hybridism. Transitory movement. Narratives.

\section{Juventud y transitoriedad: el perfil de los residentes del IRPAA y aspectos de su formación}

Resumen: Este artículo tiene como objetivo ampliar la especificidad del enfoque histórico que gira en torno a la discusión "repúblicas estudiantiles" y "juventud", así como desarrollar consideraciones teórico-metodológicas sobre la condición juvenil vivida por estos jóvenes. Utiliza metodológicamente las narrativas de 10 (diez) colaboradores, 6 (seis) jóvenes que viven y 4 (cuatro) que vivían en una república estudiantil mantenida por una organización no gubernamental ubicada en la ciudad de Juazeiro, en Bahía, en la que ofrecen, además de su estancia, posibilidades formativas en el contexto de la convivencia con el semiárido, aspecto que se opone a la formación técnica profesional a la que se someten. Presenta como principales resultados la reflexión de que estos jóvenes que son de diferentes orígenes, ya sea del campo con bases tradicionales (indígenas, quilombolas, pescadores, agricultores familiares, familia, fondo de pastoreo, movimientos sociales, etc.), se constituyen en transitorios. jóvenes, siendo el resultado del proceso de construcción del sujeto, desde la hibridación juvenil, influenciado por los movimientos transitorios, lo que constituye como principal desafío para pensar y proponer procesos de formación que atiendan las necesidades específicas de estos sujetos, ya sea en el campo educativo, de los movimientos sociales y/o la ecología humana.

Palabras-clave: Formación. Hibridismo juvenil. Movimiento de transición. Narrativas.

\section{Introdução}

Este artigo tem por interesse a discussão sobre as relações estabelecidas por jovens no seu processo formativo em curso técnico profissionalizante e sua atuação futura. Estes sujeitos vivem em uma república de estudantes mantida por uma organização não governamental situada na cidade de Juazeiro, na Bahia, em que oferecem para além da estadia, possibilidades formativas no âmbito da convivência com o semiárido, aspecto este que se contrapõe a formação técnica profissionalizante sob os quais estão submetidos.

O texto em evidência toma como centralidade os deslocamentos realizados por estes jovens no tocante a saída de sua comunidade e a chegada em espaços formativos que estão atrelados também ao convívio diário e as relações por ele estabelecida e constituinte de horizontes outros para suas vidas. Nomeamos este movimento de "transitório" e buscamos ao longo do texto problematizar esse lugar de reconstrução formativa para a vida dos jovens.

Como mencionado, o processo formativo se dá também pela convivência na república, por isso, é pertinente sinalizar que essa terminologia tem vários sentidos e significados, porém a aplicabilidade neste texto é sinônimo de hospedaria, pensionato, casa de passagens, casa de estudantes. 
Essa definição não está demarcada por uma data específica para o seu surgimento, mas, muitos estudiosos, ligam as primeiras universidades de Portugal e as casas criadas pelo governo do mesmo período. Com influência portuguesa, o Brasil teve suas primeiras repúblicas estudantis no estado de Minas Gerais, e se espalhou em várias capitais e interior do país.

Todavia um modelo, com características distintas das tradicionais, foi criada a mais de 20 anos no interior da Bahia, na região do Vale do São Francisco, com intuito de oferecer formação não formal e possibilitar que filhos de agricultores pudessem dar continuidade aos estudos, principalmente a formação técnica.

Com uma dinâmica de transição pelos quais os jovens são submetidos (vem do campo, passar por formação técnica, volta para o campo, e retornam na maioria das vezes ao urbano), provoca-nos a pensar uma condição distinta vivida por eles e que nos remetem a refletir a sua formação, participação e constituição profissional, a condição de transitoriedade, que tem contribuído para o desenvolvimento do rural e de suas comunidades, de forma justa e sustentável, graças à dinâmica da república e as influências dos processos formativos.

A perspectiva metodológica deste trabalho se constitui como um estudo qualitativo, configurado em um estudo de caso. Para tanto, vale salientar que para ser possível a realização da pesquisa definimos como lócus a república do IRPAA e os sujeitos os jovens que residem/residiram na república da instituição.

Como mecanismo de investigação lançamos mão de um instrumento narrativo, que nos permitiu aceder às memórias destes sujeitos, permeado por sua condição reflexiva de si. O uso de narrativas tem sido recorrente no âmbito das pesquisas qualitativas, especialmente as que têm caráter revelador das subjetividades como condição para avançar na construção de novas epistemologias (OLIVEIRA, 2014).

Nesse ínterim, a principal ferramenta utilizada foi o diário do cotidiano de experiência de formação ${ }^{1}$, aliado a escrita de memoriais e complementarmente entrevistas narrativas e entrevistas por profundidade, com o objetivo de construir o perfil destes jovens. $\mathrm{O}$ encontro consigo mesmo no processo de escrita de si e a reconstrução dos fatos vividos, aproximou pesquisadores e jovens sujeitos da pesquisa no intuito de permitir o avanço na concepção de categorias caras para o estudo de caráter qualitativo, sendo assim, ao passo em que as categorias foram sendo configuradas, lançamos mão da análise do conteúdo (BARDIN, 2011), como possibilidade de transposição de sentidos e condição de interpretação e compreensão dos elementos que foram surgindo e que passam a ser descritos ao longo deste texto.

Com o propósito de manter a ética, confidencialidade da pesquisa, resguardando os colaboradores, utilizaremos codinomes de pássaros e peixes da caatinga, com o intuito de manter o clima e valorização do contexto natural e lembrar o caráter transitório destes animais, caracterizado pelas suas idas e vindas, em alguns casos os migratórios.

Assim, inicialmente, trataremos os trajetos e transitoriedade da constituição dos jovens, teorizando os passos identitários ao longo da história e da constituição das distintas juventudes, em seguida, apresentamos a discussão que gira em torno das repúblicas, desde a sua gênese, a associação terminológica a hospedarias, expondo o histórico e tipos de repúblicas (fora e dentro do Brasil), chegando ao modelo de república localizado no semiárido baiano. Por fim, apresentamos a perspectiva de juventude transitória, com base no perfil institucional, por meio das vozes desses jovens.

10 desenvolvimento do diário da experiência de formação de jovens foi baseado, teórica e metodologicamente, na unificação dos princípios de dois diários, sendo eles o do diário de formação, de Miguel A. Zabalza, que está embasado na proposta de um "recurso para a reflexão sobre a própria prática e de mecanismo para o desenvolvimento pessoal e profissional” e o diário dos momentos (HESS), que surgem a partir da teoria dos momentos e têm a função de relatá-los. 


\section{A constituição dos jovens na história e a perspectiva da transitoriedade}

Muitos historiadores afirmam que, a juventude como classe social só surgiu no século XVIII, Dick (2003) ressalta que o termo juvenil só se categorizou oficialmente neste século, em que marcou definitivamente seus limites na história da humanidade.

No livro A História dos Jovens, um texto de Alain Schnapp (1996), destaca que para os gregos as cidades eram sinônimas de uma vida social regulada. Os gregos tratavam os jovens como principiantes na vida cidadã e tudo que dizia respeito a polis era tratado do mais velho para o mais novo, tendo como destaque as condutas básicas de vida helênica o ideal de beleza (a pederastia, homossexualidade) e a guerra (os jogos de caça e esforço físico). Definindo a juventude, nesta época, como o belo e o forte se firmando em seu próprio corpo as situações mais fundamentais da sua vida. Todavia, dentro deste contexto há uma contrapartida com a filosofia como nomes de Sócrates e Platão que revolucionou a educação e forma de vida grega.

Nietzsche, Sócrates e Platão, trazem uma interpretação dualista de mundo para explicar o sentido da vida e estabelecer hierarquias de princípios e valores. Nietzsche (2001), traz uma visão de Sócrates sobre a inversão moral, que cria uma terapia para harmonizar os instintos gregos dando particularidade a figura do jovem. Achando necessário redisciplinar o jovem. Usando essa dialética para o princípio da auto afirmação como um advento de defesa, transformando a regra da beleza e da fortaleza em razão, virtude e felicidade. Passando tudo pela avaliação da razão. Assim, diante de dois pontos de vista de transformação cultural do belo e da força pela razão humana, afloramos para uma nova fase da humanidade ocidental abrindo uma porta para uma interpretação da construção da subjetividade juvenil.

Christiane Marchello-Nizia (1996), ressalta que na idade média a maioria dos heróis são jovens, ou pelo menos homens com qualidades juvenis. Debruçando-se na literatura desta época, identificamos princípios ligados ao amor e proeza (cavalaria e cortesia), onde os valores ligados aos jovens nesta etapa da história estão ligados ao campo de batalha e ao claustro dos mosteiros. A sociedade era centralizada nas instituições religiosas e educacionais, que focavam em controlar as paixões carnais juvenis, que despontavam mais nessa fase e o corpo era visto como objeto de desejo, em suma era uma cultura voltada ao moralismo.

Assim, epistemologicamente podemos definir a palavra juventude a partir de diversas vertentes. Pela biologia, compreende-se em duas etapas iniciais: a pré-adolescência (de 10 a 14 anos) e a adolescência (de 15 a 19 anos), todavia, é importante sinalizar que o debate entre concepção de adolescência e a ideia de juventude se constitui com amparos teóricos distintos, que nos permitem avançar para o lugar de subjetividade a que se propõe esse trabalho. $\mathrm{O}$ antagonismo que se estabelece com a ideia de juventude e adolescência é o que nos provoca a trazer para o texto outras percepções.

Para a sociologia, a juventude é configurada com um interstício estabelecido entre as responsabilidades da criança e do adulto, ao passo em que são incorporadas no seu cotidiano, é possível estabelecer o espaço limítrofe entre o mundo adulto e a presença da juventude (OLIVEIRA, 2014). A antropologia entende a juventude como um elemento cultural enriquecedor. $E$ a história trata a juventude como uma variante temporal, espacial e cultural dependendo da sociedade inserida (CLÍMACO, 1991).

Os trajetos juvenis no país deram-se a partir do movimento abolicionista no século XIX, esses jovens intervieram na atuação radical pela libertação dos escravos (CACCIA- BAVA, 2004). Em 1920 três movimentos em prol da juventude política foram inaugurados: o Movimento da Semana da Arte Moderna; o Movimento Tenentista e o Movimento político partidário que originou o partido político PCB. Para Caccia-Bava (2004, p. 64), "os grupos de jovens se formaram em torno desses movimentos e foram protagonistas de novas ideias, novas concepções de nação e de Estado".

Tivemos então uma organização juvenil com movimentos voltados à nacionalidade como destaque a União Nacional Estudantil - UNE e o movimento religioso em torno da Ação Católica. Segundo Novaes (2000), os jovens que pertenciam às organizações partidárias e sindicais 
representavam a classe trabalhadora. Destacando a década de 1960 que foi quando a juventude passou a ter ênfase na sociedade brasileira. Porém devido à efervescência política dos anos que sucederam da década de 60 por causa da Ditadura Militar a juventude exerceu uma articulação interna de cunho espiritualista, e os jovens que resistiam a esse sistema atuavam nos movimentos sociais clandestinos de luta armada.

Nos anos que antecede aos anos 1990 nos deparamos com uma juventude não portadora de utopias, de acordo com Sousa (1999, p. 25): "Intenções, utopias, projetos, rebeldias, transgressões são elementos concretos nas relações vividas por essa faixa etária, mas, isolados como comportamentos próprios dos jovens, não são explicativos das relações que envolvem a juventude". As condições sociais dos jovens dos anos 90 são distanciadas dos métodos revolucionários, e o que é notado é uma perspectiva individualista.

Como já foi abordado, não há uma faixa etária universal exata para delimitar esta fase da vida, assim, como já foi dito, a mais citada e utilizada por diversos territórios é entre 15 e 24 anos, com base na UNESCO e, principalmente, na ONU: "Youth and Young People - The UN Secretariat uses the terms youth and young people interchangeable to mean age 15-24 with the understanding that member states and other entities use different definitions" ${ }^{2}$, assim como citado, haverá casos em qual o país ou continente, definirá com base em seus estatutos ou regimentos a idade inicial e final.

Assim, como foi dito anteriormente, com relação às variações de faixa etária, na África do Sul, a faixa etária, ficam entre 14 a 35 anos (OUA, 1996), já no Canadá há variações com base na sua distribuição geográfica, geralmente têm variações de 12 a 19, ou em alguns casos de 15 a 19. Já os britânicos, dita que não há uma idade inicial exata, porém termina com 30 anos. No Japão os jovens são indivíduos com até 35 anos de idade (CHAVES JÚNIOR, 1999).

Em outros países ocidentais definem a idade máxima da juventude para 15 anos de idade, mas isso vai depender dos aspectos culturais. A juventude é uma categoria que além de ser marcada pela adversidade é uma classe dinâmica. E a partir de uma nova conjuntura familiar, política e social o jovem está inserido em processo de sociedade transitória.

Entretanto, alguns especialistas (PAIS, 2003; OLIVEIRA, 2014) consideram a juventude como a fase de transições, o interstício entre as responsabilidades de criança e adultos na sociedade, ou seja, assumem papel social, indo além do que uma faixa etária. No entanto, os órgãos oficiais, como o IBGE, determinam dos 15 aos 24 anos. Já o Estatuto da Juventude (BRASIL, 2013) considera-se jovem no Brasil todo o cidadão com idade entre 16 e 29 anos e por fim o Estatuto da Criança e do Adolescente (ECA) estabelece que adolescente é o indivíduo entre 12 e 18 anos. Deste modo, podemos considerar algumas variantes, divididas em três estágios: os adolescentes-jovens (entre 15 e 17 anos), os jovens-jovens (com idade entre os 18 e 24 anos) e os jovens adultos (faixa-etária dos 25 aos 29 anos).

Completando a discussão e dando continuidade, a juventude pode ser definida por suas culturas, crenças, ideologias (ideias, pensamentos, doutrinas e visões de mundo) e origens (rural, urbana e rururbano), ou, até mesmo, por períodos (anos dourados, hipers, caras pintadas, etc.). Ou seja, "[...] a juventude é uma concepção, representação ou criação simbólica, fabricada pelos grupos sociais ou pelos próprios indivíduos tidos como jovens, para significar uma série de comportamentos e atitudes a ela atribuídos" (GROPPO, 2000, p. 7).

Os jovens, estão vivendo em constantes mudanças e adaptações, inseridos em um contexto globalizado/tecnológico que engloba a quarta revolução industrial, com o uso de computadores, tablets e celulares de última geração que acabam anulando distâncias que antes existiam e dando a acesso a todos os tipos de informação seja para o campo ou para cidade. "[...] devido à sua combinação com outras situações sociais - como a de classe ou estrato social - e, devido também às diferenças culturais, nacionais e de localidade, bem como às distinções de etnia e gênero" (GROPPO, 2000, p. 15). 
Assim, principalmente a juventude rural ou do campo, que antes era marcada pela "ignorância" negação dos direitos, agora traça um caminho de desenvolvimento na educação, cultura e lazer.

Sabe-se que sempre existiu o contexto do êxodo para os grandes centros no anseio de uma condição de vida melhor. No âmbito juvenil atualmente buscamos uma inserção como sujeito singular na sua constituição identitária e plural nas suas necessidades particulares e assim passamos a identificar como jovens transitórios.

Objetivando ampliar a discussão e adentrar no universo da transitoriedade dos jovens, principalmente os jovens de origem do campo e migram para o urbano em busca de estudo/ trabalho, a nova moradia, onde muitas vezes são ambientes compartilhados, contribuem para a construção da identidade desses sujeitos.

\section{A vida na república: do transitório ao sujeito social}

A origem do termo "república", tem genealogia do latim res publica, palavra que pode ser expresso como assunto público ou coisa pública, que denota a ideia de bem público, do que é coletivo (LAFER, 1989). O regime abordado pelo império Romano (república romana), também foi utilizado para classificar as cidades-estados da Grécia, ou o regime instituído por Oliver Cromwell no século XVII na Inglaterra (MENDÉS-FRANCE, 1963). Entretanto, a concepção moderna de república (baseia-se em um chefe de estado e na divisão de poderes) só surgiu depois do fortalecimento do liberalismo.

Assim, a terminologia república ganhou adjetivos e foram associadas às moradias estudantis, casas comunitárias de estudantes, pensionatos, pensão ou Irmandade, todavia há diversas suposições (REPOLÊS, 2007), assim, esses tipos de moradias são compostos por grupos de jovens, na maioria das vezes são de localidades distantes e se deslocam em busca de estudo (MACHADO, 2013a).

Com relação aos primeiros registros sobre repúblicas, existem várias versões, a mais citada é que no século XIV em Coimbra, Portugal, quando D. Dinis, por diploma régio de 1309, requeria a construção de casas deveriam ser habitadas por estudantes na zona de Almedina, por meio de um pagamento fixo de um aluguel, administrado por uma comissão indicada pelo Rei, composta por estudantes e por "homens bons" da cidade. Deste modo, esses tipos de alojamento, possibilitava a universalidade do ensino superior, permitindo que jovens de diversas localidades continuem seus estudos.

Já no Brasil, as repúblicas de estudantes têm sua origem a partir das primeiras faculdades criadas na regência de Dom João IV, como a Faculdade de Medicina em 1808, mais na frente com Dom Pedro II, com a implementação da Escola de Minas em Ouro Preto em 1876, se tornaram o centro da vida estudantil, incorporando tradição, história e costumes próprios (MACHADO, 2013c). Assim, próximo a Escola de Minas foram criadas repúblicas de estudantes, nos mesmos modelos das de Coimbra, destacando que as casas eram de propriedade da Escola, com a mudança da capital para Belo Horizonte em 1890, e passada a responsabilidade e manutenção aos estudantes, atribuindo um pequeno aluguel (MACHADO, 2013b).

Desta forma, as repúblicas de Ouro Preto em Minas Gerais, são denominadas únicas no Brasil (MALTA, 2010), graças a suas particularidades, ditas inigualáveis a outras cidades universitárias, tendo as características de moradias estudantis, com sua tradição, história e constituição de estrutura, assemelhados) às repúblicas e solares de Coimbra, em Portugal.

Outra informação é pertinente para esta discussão é a criação da primeira república fora do país, destinado aos estudantes brasileiros em Paris, denominada de "casa dos estudantes" criada em 1928, localizada em Paris, e direcionado a auxiliar estudantes que estudavam na capital da França e tinham dificuldades em se manter na cidade (COSTA, 2010). 
Com o passar dos tempos, as repúblicas estudantis, foram se multiplicando ao longo dos anos e território brasileiro, agregando as mais diversas modalidades de ensino, desde o ensino fundamental e médio, um exemplo na perspectiva da pedagogia da alternância ${ }^{3}$, como também no ensino técnico oferecido pelas escolas técnicas e institutos federais e por fim no superior, desde as instituições estaduais e federais, no qual "[...] em algumas instituições existem residências universitárias, onde é disponibilizada toda a infraestrutura, tal como quartos mobiliados e com eletrodomésticos, enquanto em outras é fornecida uma bolsa destinada ao pagamento dos gastos com moradia com valores variados" (IMPERATOR, 2017, p. 295).

Assim, há uma diversidade de tipos de repúblicas, no qual parte delas fazem parte do plano de assistência estudantil, onde as instituições ofertam moradias (dentro ou fora da instituição) mantida pela e em outro caso, as moradias são mantidas pelos os próprios estudantes com recurso da assistência ou ajuda familiar. Assim as repúblicas ou moradias destinadas a jovens de outras localidades que vão em busca de continuar seus estudos, existem no Brasil e a séculos e ultimamente tem ampliado e ganhado a interiorização em diversas regiões e estados.

Um modelo de república, localizado no semiárido ${ }^{4}$ baiano, que já tem mais de duas décadas de existência e recebe anualmente grupos de jovens com origem do campo e comunidades tradicionais, que migram em busca de dar continuidade nos estudos, principalmente na formação técnica e poder contribuir para o desenvolvimento regional e local das comunidades dos sujeitos. Sendo esta hospedaria, a centralidade deste estudo, uma vez que possui características singulares dos modelos descritos ao longo deste material, dando origem a um termo denominado Jovens transitórios, que mais adiante será detalhado.

Para adentrar na contextualização da república que iremos discutir, inicialmente apresentamos a instituição que administra, Instituto Regional da Pequena Agropecuária Apropriada IRPAA, fundada a quase 30 anos, é uma Organização Não Governamental com sede no município de Juazeiro-BA, que desenvolvem ações de sensibilização e conscientização por meio de projetos educativos e de ações concretas, para a convivência com a seca é o semiárido (OLIVEIRA, 2005; CARVALHO, 2008; OLIVEIRA, 2014).

Uma vez, o IRPAA tornando-se referência em estudos e formações, para a convivência com o semiárido, foi necessária, a ampliação de suas instalações assim como a criação de um centro para a realização das formações, assim em 1994, foi criado o centro de formação Dom José Rodrigues ou popularmente conhecido como roça do IRPAA, localizada a $12 \mathrm{~km}$ da cidade de Juazeiro-BA, no bairro Jardim Primavera na fazenda Tourão, com 30 hectares, o espaço conta com auditório, dormitórios, refeitório, além dos experimentos (diversos tipos de cisternas, fábrica de beneficiamento, hortas, criadores de animais, barreiro, etc.), todo essa estrutura serve de base para a realização de diversos eventos (encontros, seminários, conferências, etc.), podendo abrigar até 60 pessoas.

Além da perspectiva de um espaço de formação, a instituição agregou a roça, uma república formada por duas casas (feminina e masculina), destinada a receber jovens de origem do campo, filhos(as) de agricultores(as) de diversas localidades do semiárido brasileiro, que possuem sociedades com instituições parceiras, que buscam ingressar em cursos técnicos ou superiores na área agrária/ambiental. Em contrapartida, a instituição oferece uma formação informal em diversas áreas e habilidades, desenvolvendo o senso crítico, político para novos nortes e principalmente para a conservação e convivência com o bioma caatinga e o semiárido.

\footnotetext{
3 É um método que busca a interação entre o estudante que vive no campo e a realidade que ele vivencia em seu cotidiano, de forma a promover constante troca de conhecimentos entre seu ambiente de vida e trabalho e o escolar. Disponível em: http://portal.mec. gov.br/component/tags/tag/36222-pedagogia-da-alternancia.

4 O Semiárido brasileiro representa $11,39 \%$ do território nacional e abriga $29 \%$ da população do País. Com extensão de $969.589,4$ km² representando cerca de $62 \%$ do território nordestino (incluindo a parte Semiárida de Minas Gerais). Com precipitação pluviométrica média anual inferior a 800 milímetros; índice de aridez de até 0,5; e risco de seca maior que 60\%. Disponível em: http://www.irpaa.org/modulo/fundamentos.
} 
As manutenções dos espaços da roça e da república, são realizadas pelos jovens residentes, que realizam atividade de conservação como limpeza, capinação, alimentação dos animais, compostagem, entre outras atividades, em horários que não comprometam os estudos. A fonte de sustento na instituição se dá por bolsas de apadrinhamento ${ }^{5}$ (SILVA, 2004, p. 27), para manter os custos pessoais e não induzir os jovens a buscarem trabalho e focarem apenas nos estudos. Além disso, na firmação do contrato com o IRPAA, é feito um acordo com os jovens, no qual, após concluírem o curso, eles devem voltar a suas comunidades e durante um período, devem fazer uma devolutiva, assim como é apresentado em algumas narrativas dos colaboradores a seguir:

[...] por outro lado, eu estava com a formação técnico em agropecuária, então meu pensamento foi que, ali seria o momento em que eu iria voltar para minha terra, pra contribuir [...]. (PACUMÃ, memorial de formação, 2018).

[...] o acordado entre o IRPAA e a instituição que nos indicam, que no final do curso técnico, retornamos para repassar os conhecimentos e aplicar em nossa comunidade, [...]. (DOURADO, diário do cotidiano, 2017).

A república suporta 24 jovens no máximo, que realizam rodízios para visitarem as suas comunidades, principalmente em datas comemorativas, para visitarem os familiares. Assim, todos os anos, um grupo novo chega e outro se despede da instituição. Nesta dinâmica de idas e vindas, com a fixação de um período nas comunidades, geram uma transitoriedade, no qual denomino de “jovens transitórios". Assim, ao longo de mais de 23 anos, já passaram mais de 150 jovens, que tecem um grupo e geração, com grande responsabilidade para o desenvolvimento de suas bases.

\section{Quem são os jovens residentes do IRPAA: aspectos da transitoriedade e formação}

A região nordeste é conhecida pela sua grande extensão territorial, além de abrigar a maioria dos estados brasileiros, região rica em diversidade cultural, climática e geográfica, tem uma grande variedade de biomas, entre eles a mata atlântica e mangue (litoral), floresta amazônica (oeste da região), mata dos cocais, cerrado e com maior extensão e predominância o ecossistema com caracterizado semiárido, denominado bioma caatinga, no qual sempre foi repassado uma imagem e visões estereotipadas principalmente no interior e no campo, de um local de atraso e de desgraças, povo matuto, analfabeto e desnutrido, chão rachado, animais mortos, com uma crença que dizia que nada aqui dava certo, pois era a vontade de Deus. Restando apenas uma direção, migrar para as cidades, que eram sinônimos de progresso e modernização, assim por décadas, principalmente nas grandes secas, milhares de nordestinos buscaram as regiões metropolitanas, principalmente na região sudeste, como alternativa para se livrarem das secas.

Com isto, diversas ações e programas foram implementados pelos governos, objetivando erradicar e combater a seca, como o DNOCS e SUDENE ${ }^{6}$, entre outros, porém as ações enxergavam que a seca era algo negativo e deveria ser detido a qualquer custo, não vendo que se trata de um fenômeno natural desta região. Assim nas últimas três décadas, foram energizadas as ações para

\footnotetext{
5 "O método utilizado foi o de apadrinhamento individual da criança. Na década de 60, o enfoque começou a mudar: passou-se dos órfãos de guerra aos carentes dentro de suas próprias famílias. Quatro anos depois, em 1964, expandiram o programa para o terceiro mundo" (SILVA, 2004, p. 57), assim, como o exemplo citado, trata-se de um programa filantrópico, destinado a crianças e jovens do sertão mineiro, assim, existem diversos outros projetos/programas não governamentais de apadrinhamento no Brasil, ex: Save The Children, Caritas Alemã, China'children Fund, Fundo Cristão, Achante, etc.

6 As políticas de "Convivência com o Semiárido", do governo federal empreendia o "combate à seca" - desde que o imperador Dom Pedro II com a construção do açude do Cedro, uma das primeiras grandes obras públicas de combate à estiagem, em 1880, passando pela fundação do atual Departamento Nacional de Obras contra a Seca - DNOCS, que se deu em 1909, e, na segunda metade do século 20, da Superintendência de Desenvolvimento do Nordeste - SUDENE. Disponível em: http://www.irpaa.org/publicacoes/artigos/1075-4041-1-pb.pdf.
} 
conviverem, principalmente das organizações da sociedade civil, movimentos sociais, organizações dos agricultores (as) familiares, camponeses (as) e lideranças (COSTA, 2017), criando um novo "paradigma na lógica da Convivência com o Semiárido que assegure a perspectiva do Bem Viver?, por meio de uma relação sustentável dos seres humanos e natureza" (COSTA, 2017, p. 95.)

A iniciativa de criação da instituição se deu pelo Bispo Dom José Rodrigues da Diocese do município de Juazeiro, que seguia os ideais do bem viver, e contra algumas proposta governamental (combate à seca), além de militante pelas causas dos menos favorecidos no campo e na cidade, no qual organizações e cooperação internacional junto com as Comunidade Eclesiastes de Bases - CEBs, iniciaram um coletivo de ações locais e regionais, com o objetivo de minimizar as consequências da seca prolongada.

Nesse contexto, surge em abril de 1990 o Instituto Regional da Pequena Agropecuária Apropriada - IRPAA, organização da sociedade civil organizada, não governamental e sem fins lucrativos, regida juridicamente por uma associação, com representações das dioceses, dos agricultores/as e de lideranças regionais, que a princípio se nutre das experiências e dos modos de vida das comunidades rurais e, em primeiro momento, formula uma proposta diferente para essa região, a partir do conhecimento local, identificando as potencialidades e as fragilidades, aprendendo com a natureza a lidar com as situações adversas de oscilações climáticas, respeitando as especificidades locais, valorizando a cultura de um povo forte e resistente, povo de muita fé e crença, que mesmo com o acentuado êxodo rural, ainda tem esperanças de dias melhores no campo. (COSTA, 2017, p. 88-89).

Com a criação do IRPAA, diversos aspectos relacionados a convivência com o contexto geográfico, biológico e climático, passou a ser visto de outras formas, da "seca desgraçada" a "uma realidade climática, no qual devemos conviver e buscar meios para sobreviver", esta é a missão e militância do IRPAA, desta forma organizada em três períodos, segundo Costa (2017), onde entre os anos de 1990-1999 teve como estratégia institucional a construção e divulgação da proposta de Convivência com o Semiárido; entre 2000-2009 com a defesa de uma política pública apropriada para o Semiárido e por fim 2010-2017 com estratégia em construção atualmente, perpassa pela Consolidação da Convivência com o Semiárido.

Retornando ao subtópico anterior, com a criação do IRPAA, foi agregado aos espaços físicos, o centro de formação Dom José Rodrigues (inicialmente era nomeado apenas como roça do IRPAA, em homenagem ao fundador é que passa a ser assim nomeado) como parte estrutural das repartições do mesmo, onde serve de laboratório e centro de formação para a convivência com o semiárido. Aproveitando o espaço, além das iniciativas internacionais, foi implementado ao mesmo espaço, a criação de uma república voltada para receber os filhos(as) de agricultores e povos tradicionais, a fim de dar continuidade aos estudos (técnico e superior).

Ao longo de 24 anos (1994-2018), centenas de jovens passaram pela república da instituição, compartilhando e divulgando os princípios e ideias para a convivência com o bioma caatinga, entre idas e vindas, trilharam e trilham uma missão do Bem Viver. Para a construção desta pesquisa, participaram dez colaboradores, dentre eles seis jovens que residem na república e quatro que viveram e passaram pelo processo de formação.

A seguir apresentamos os colaboradores, utilizando codinomes para garantir a ética da pesquisa e resguardar os sujeitos ${ }^{8}$. Para este momento, utilizaremos de trechos do diário do cotidiano

\footnotetext{
7 “O Bem Viver defende que se 'assegure' qualidade de vida, em um sentido ampliado que transcende a dimensão material, individual e antropocêntrica em benefício de um certo bem-estar espiritual e comunitário que se estende a toda Natureza. O Bem Viver valoriza a Natureza em si mesma. Portanto, deseja manter sua integridade local e globalmente. Isso faz com que essa perspectiva esteja orientada a transcender o dualismo que separa sociedade e Natureza, e também a romper com a concepção de uma história linear, segundo a qual nossos países devem repetir os estilos e a cultura das nações industrializadas." (GUDYNAS, 2016, pág. 182).

8 Número de aprovação no CEP: CAAE: 65610517.0.0000.0057/número do parecer: 2.024.523. Com base nos procedimentos éticos da pesquisa, foi resguardado os nomes dos colaboradores e atribuídos codinomes para manter o sigilo deles.
} 
de experiência de formação, memoriais e entrevistas narrativas e por profundidade, para sua apresentação. Para isso, utilizaremos nomes de espécies de peixes e aves da caatinga, uma vez que são animais sinônimos de resiliência, força e pelo seu caráter transitório de idas e vindas.

Inicialmente apresentamos os estudantes Tiziu, Asa-Branca, Surubim e Pacumã, poderão observar que este tem como semelhante a passagem e vivência na república e a constituição como profissionais partindo destas experiências.

Natural de uma comunidade rural chamada Lagoa da Roça, município de Campo Formoso na Bahia e criado pelos avós maternos, desde cedo fui instruído a participar dos espaços religiosos, igreja católica, e espaços coletivos de discussões na comunidade, associação comunitária, além do envolvimento nos trabalhos da roça onde plantávamos feijão, milho, mandioca, batata, guandu, abóbora, melancia e nos dias de sábados íamos vender esses produtos na feira livre do município. (Tiziu, memorial de formação, 2018).

Eu Asa Branca, 35 anos, filha adotiva de pequenos agricultores camponês, Maristela Santos de Santana e Edmundo Ferreira residente e domiciliada na comunidade Itapicuru Monte Santo Bahia, venho através deste relatar minha trajetória de vida pessoal e profissional. [...] desde muito cedo, quando ajudava meu pai nos trabalhos da roça e participava dos acontecimentos e iniciativas populares junto a minha mãe professora, líder comunitária e defensora de uma classe oprimida, a qual tanto almejava um grande sonho, juntamente com várias tantas outras lideranças dar-nos, apoiar-nos enquanto filhos de agricultores(as) do campo uma educação qualificada que defendesse e discutisse a realidade, a vida do jovem camponês. (Asa Branca, memorial de formação, 2018).

Eu sou Surubim, tenho 24 anos, acidente geográfico Chorrochó-Bahia, Escorpiana, carrego comigo sangue indígena, mistura com mulatos, minha bisa era índia os trukas, técnica em agropecuária, mãe do Miguel, venho da comunidade Alto Vermelho município de Abaré, BA, comunidade qual é reconhecida como fundo e fecho de pasto, filha de agricultor e agricultora, venho da luta, fiz parte dos movimentos sociais, fiz parte também do grupo gau: grupo de agroecologia Umbuzeiro, que fina na Universidade ENEB/Juazeiro, em 2014 fiz parte da república do IRPAA. (Surubim, memorial de formação, 2018).

Sou Pacumã, sou filha de agricultores familiares, minha mãe e meu pai, sempre trabalharam na roça, assim como os meus avôs, tanto materno como paterno, [...] meu pai sempre trabalhou na roça, tanto na cultura do cajueiro, [...] e criava cabras, ovelha e galinhas, [...] naquele tempo eu não enxergava a importância da agricultura no campo [...], eu via a roça como algo ruim que não era bom pra mim [...], e via que deveria crescer e ir em busca de novos objetivos, [...] só que para isto eu deveria ir para São Paulo ou Rio de Janeiro, como muitos daqui [...] foi aí então que meu primo [...] começou estudar na escola [...] EFA de Crateús-CE próximo a minha cidade [...], daí meus pais se interessaram [...], eles viam uma oportunidade de mudança pra mim, ai que passei a estudar nesta escola [...]. A vivência na escola agrícola, [...] eu passei a enxergar o semiárido como algo bonito [...] eu acreditei, que poderia crescer e me tornar alguém melhor [...]. Uma certa vez, tiziu e Neidinha foram visitar a escola, e falaram da república que o IRPAA, colocaram como um excelente lugar de aprendizagem e de estudo para os alunos, que eles davam apoio financeiro, [...] de uma bolsa, [...] eu falei com meus pais, do meu desejo de ir para Juazeiro, [...] eu não tinha condições de ir e nem me manter naquele momento, pois no primeiro ano não teria a bolsa [...] meu tio avô, disse que me ajudaria naquele momento, [...] meu tio e minha mãe me deram apoio [...] eu fui com meu primo e um colega da comunidade [...], que também fizeram parte da república [...]. (Pacumã, memorial de formação, 2018).

Ao narrar e apresentar-se, os jovens fazem um movimento de encontro com as diversas temporalidades que os constituem e vão significando a dimensão de transitoriedade do qual estamos fazendo referência ao longo do texto. Seguiremos apresentando as narrativas dos atuais estudantes que vivem na república do IRPAA e compõe o movimento transitório nestes sujeitos e os seus espaços. 
Desde a infância, fui menino de igreja, menino comum, igual a todos, mas, religioso, isso se deve ao incentivo de minha mãe, embora não muito religiosa, sempre me levou à encontros de grupo, reuniões das quais participava, tudo isso ligado à igreja Católica. [...] até fundador de um grupo de oração e outro de canto e sendo membro de um grupo de Jovens. [...] Canudos; cidade histórica, [...] cidade de gente simples e acolhedora que mesmo com influência midiática e com as politicagens partidárias, tentam manter o espírito de fraternidade. (Caburé, diário do cotidiano, 2017).

Sou da comunidade Caraíba de Senhor Teixeira, município de Pilão Arcado em minha comunidade mora só família tem seis casas. Praticamos atividades voltadas a agricultura e pecuária onde criamos gado, ovelhas, cabras, galinhas, produzimos farinha, tapioca, etc. o que me trouxe a esse curso foi a necessidade técnicas em agropecuária em minha região além de ser uma área que me identifico [...]. Na minha comunidade eu trabalhava como catequista e nas comunidades vizinhas pôr a igreja católica participava de encontro que era promovido por a paroquia Santo Antônio em Pilão Arcado onde vinha jovem do município todo no centro de formação Palmeiras de Elim onde tinha encontro de estudos de bíblia, assembleias entre um espaço muito agradável [...]. Também sempre gostei de participar de reuniões de associações ou qualquer do tipo. Sempre participei de reuniões promovidas pelas entidades IRPAA e SASOP [...] dos encontros promovidos pela pastoral da Terra-CPT que também me ajudou a escolher cursar agropecuária onde eu já tinha conseguido uma vaga para estudar na EFAS de Monte Santo [...]. (Piau, diário do cotidiano, 2017).

Sou azulão, venho do interior de Campo Formoso, tenho 21 anos (Jardel), filho [...], tenho duas irmãs [...] ambas mais novas. Mãe é dona de casa e também trabalha na roça, pai trabalha em construção civil[...] terminei os estudos em 2014 foi quando comecei a trabalhar mais meu pai, na construção civil. Trabalhei dois anos com ele. [...] venho de uma família simples do interior de campo formoso, onde fui criado pelo meus pais com a ajuda de meus avós paterno, uma infância um pouco difícil por não ter condições financeiras [...], fiquei sabendo do IRPAA através do meu tio que, morou na república. (Azulão, diário do cotidiano, 2017).

Sou arribaçã, tenho 21 anos e venho de uma comunidade indígena da tribo tuxi do município de Abaré-BA. Ainda sou agricultora, índia e atualmente estudante do curso de engenharia agronômica e filha de agricultores na qual o principal sustento foi o manejo com a mãe terra, desde aos 11 anos comecei com trabalhos de grupos na igreja de minha comunidade e logo depois com o passar do tempo com a causas indígenas do meu povo tuxi. (Arribaçã, diário do cotidiano, 2017).

Sou carcará, de uma comunidade quilombola, [...] do povoado de Tamanduá, [...], tenho orgulho de ser remanescente de quilombola de um povo resistente, lutador que mesmo com o sofrimento conseguem manter-se forte e luta por seus direitos, que durante muitos anos foram negados [...]. (Carcará, diário do cotidiano, 2017).

Meu nome é dourado, tenho 20 anos, [...] somos 3 irmãs, [...] já moramos em Brasília por oito anos e voltei em abril de 2008, foi quando terminei a $4^{\text {a }}$ serie, em Lagoa de Eduardo, comunidade de Pilão Arcado, mais eu moro em sitio Geraldo, [...] porém tive que repetir de ano, pois minha mãe achava que não estava preparada para a $5^{\mathrm{a}}$ série [...] das três irmãs, uma faz pedagogia, e a mais nova está parada, pois mão não tem condições de pagar, [...] a minha vinda para IRPAA, foi graças a colega, que estuda em Monte Santos, na EFA, que é da comunidade, que falou, [...] eu era secretária da associação, [...] ai o gerente pastoril me indicou a associação de fundo de pasto, que me indicou, [...] eles viram o meu envolvimento na comunidade, [...] antes de vim, eu estava preocupada, vou terminar o ensino médio e vou fazer o que, [...] os professores perguntava o que a gente ia fazer, qual faculdade, mais a gente não sabia [...]. (Dourado, diário do cotidiano, 2017).

Como visto, boa parte dos que passaram ou vivem na república, tem algumas características comuns, entre elas, a origem dos movimentos sociais, comunidades tradicionais (campo, pescadores, indígenas, quilombolas, agricultores, entre outros) ou relação com a igreja ou a grupos relacionados. 
Tendo em vista que todos compartilham de ideais, costumes, culturas, hábitos e práticas, voltada para uma cultura sustentável e ecologicamente correta, assim, os envolvidos com a república, estão em constante formação, principalmente a informal e não formal, por conta da diversidade da convivência e as políticas da instituição.

São estes aspectos que possibilitam pensarmos em jovens transitórios que se constituem inicialmente pelo perfil traçado pela instituição, ao criar critérios de inclusão, com base nos regimentos interno, termos de adesão. Esses jovens vêm de comunidades tradicionais, sejam elas, de pescadores, quilombolas, indígenas, fundo de pasto, famílias que vivem do extrativismo de frutas agricultores familiares.

Todavia, há suas exceções, alguns jovens que passaram pela república foram indicados por movimentos sociais, ligados à igreja, como o caso do jovem Caburé, que vem do município de Canudos-BA, por indicação da igreja católica e da CEB, sendo que mesmo assim, aplica-se o critério de serem de municípios de pequeno porte, com uma cultura/comércio voltado para o campo, onde alguns estudiosos, apresentam que a expansão destes espaços, deu a origem de pequenos vilarejos, e por sua vez, em pequenos municípios, no qual, não deixa de ser um ambiente rural desenvolvido, como alguns autores costumam chamar de rururbano (CARNEIRO, 1998; SILVA, 2004), urbano-rural (BERNIERI, 2002; REIS, 2006). Assim, para este estudo, os jovens da república, estão sempre associados ao campo, uma vez que a centralidade, além dos processos de formação é destinado a este perfil de sujeito.

\section{Movimentos transitórios e os jovens como sujeito social}

A categoria de transitoriedade é forte e associável à juventude, como se a natureza tendesse a um processo de mudanças e adaptações. Assim, para aprofundar a discussão de um grupo específico (jovens da república do IRPAA) é necessário adentrar no universo epistemológico de alguns termos e categorias, para uma melhor compreensão.

Oliveira (2014), trata de umas das características dos jovens que residem ou já passaram pela república do IRPAA, onde os processos de construção (identidade, gênero, profissional), associados a diversidade cultural dos espaços no qual os jovens estão inseridos (IRPAA e CETEP), além das idas e vindas de suas comunidades, para além das transformações subjetivas e pessoais, ocasiona numa nova reflexão sobre si, no qual o autor identifica como um processo de hibridismo.

A transição na fase juvenil, ocorre em ambos os espaços (rural e urbano), este movimento é mais visível e forte, quando tratamos de jovens do campo, que muitas vezes está tendo contato pela primeira vez com uma cultura urbana/globalizada. Este movimento entre idas e vindas (república-escola; república-comunidade) dos jovens da república, contribuem para o movimento de hibridismo, reconfigurando o indivíduo, dando a oportunidade de reavaliar seu papel como sujeito naquela comunidade.

Pensar a juventude que habita as repúblicas do IRPAA se constitui numa condição transitória, que está diretamente relacionado ao desenvolvimento do indivíduo (jovem), marcada inicialmente pela sua história, religião, cultura e costumes e passa a ter influências diretamente culturais e sociais, do contexto no qual está inserido. Para além disto, outras influências são constantes na vida dos jovens do IRPAA, os mesmos estão vivenciando uma fase/processo de formação, que neste caso de duas instituições, onde a oferecida pelo CETEP (curso técnico = formal) e a do IRPAA (formações interna, capacitações, cursos e minicurso = não formal), que introduzem múltiplos conhecimentos e ideologias nos residentes, no qual são processados, decodificados e repassados ou reproduzidos nos seus círculos de convívio.

Apresentamos a seguir uma sequência de narrativas que caracteriza o movimento transitório que constitui estes jovens, 
[...] eu tinha uma visão sobre a sociedade, sobretudo, com a minha vivência aqui no IRPAA, as formações, até mesmo alguns disciplinas no CETEP, eu pude mudar o meu ponto de vista, [...] a formação política como exemplo, [...] quando eu fui na folga a minha comunidade, já via com outros olhos a postura de meus amigos, que é muito machista, homofóbicos, e não é desse jeito, todos são iguais e têm o mesmo direito, ao voltar para república, pude ver o quanto mudei para melhor. (Azulão, diário do cotidiano, 2018).

[...] hoje eu surubim, estou contribuindo, com meus conhecimentos adquirido no IRPAA e CETEP, na cooperativa de Uauá, Curaçá e Canudos COOPERCUC; na região de Curaçá em um território quilombola, que é o quilombo de Valdemar, na Nova Jatobá, tem pouco tempo, mas já tenho projeto, para a comunidade e confesso diante de tudo que passei, dei um tapa na cara da sociedade, a quem não esperava por isso; to dando o melhor de mim, que não é pouco, rsrsrs... tô muito feliz apesar que demorei muito para exercer a minha profissão mas tudo no tempo de Deus. (Surubim, diário do cotidiano, 2018).

Com base nos relatos, observamos que do ponto de vistas diferentes, a vivência e convivência nesses espaços, caminham para uma transformação, que se ocorre a cada ida e vinda, de avaliações e reavaliações e por fim, pela reflexão.

Com todos os elementos aqui explicitado, acreditamos que especificamente relacionada a estes jovens que são de origens diferentes, seja do campo com bases tradicionais (indígenas, quilombolas, pescadores, agricultores familiares, familiares, fundo de pasto, movimentos sociais, etc.), se constituem como jovens transitórios, que é o resultado do processo de construção do sujeito, a partir do hibridismo juvenil, influenciado pelos movimentos transitórios.

Retomando a discussão, o termo transitório, discutido por Oliveira (2014) na sua dissertação de mestrado, aqui é ampliado e fortalecido. Para uma melhor compreensão, o termo está associado a algo que está em constante movimento, encontra-se em um processo transversal, perpassando por outros processos e movimentos. Desta forma, observamos os jovens do IRPAA em um processo, totalmente diferente de outros jovens que se encontram na mesma dinâmica, residindo em repúblicas, porém, estes com subjetividades e entrelaçados de formas diferentes.

\section{Conclusão}

O cotidiano revelado por estes jovens ao narrarem-se e refletirem acerca de sua condição juvenil, condição esta que corrobora com o apresentado por Dayrell (2003) ao vincular o debate a dimensão de transitório como possibilidade do "vir a ser", assim também os jovens vão aos poucos fortalecendo-se e tecendo aprendizados que os possibilitam apresentar-se não apenas com uma idade pré-fixada que determina se estão, são ou não jovens, está para além de uma categoria, que vai se constituindo distante dos modos de viver e ser na sociedade, apresentam-se como construtores dos seus processos formativos e desta forma consideram cada elemento como significativo para que avancem e assumam os papéis e funções sociais diante de sua atuação pessoal e profissional.

O que salta na leitura das narrativas e o contato com estes sujeitos é de que a transitoriedade que constitui estes jovens está delineada por questões subjetivas que se fazem presentes nas suas marcas identitárias e permitem desta maneira refletir o movimento de ir e vir, presente na sua trajetória formativa, em que são levados a sair de suas residências, do seio familiar, daquilo que é considerado "zona de conforto", para viverem o diferente, o imprevisível, todavia não se caracteriza como elemento permanente, há uma presença da efemeridade que marca esse movimento transitório que vivem.

Para além destes aspectos, é pertinente elucidar que em suas narrativas o lugar do transitório como movimento de construção e reconstrução identitária é reforçado e se configura como possibilidade de diálogo com o seu processo formativo. Dayrell aponta que 
Por outro lado, nos deparamos no cotidiano com uma série de imagens a respeito da juventude que interferem na nossa maneira de compreender os jovens. Uma das mais arraigadas é a juventude vista na sua condição de transitoriedade, na qual o jovem é um 'vir a ser', tendo no futuro, na passagem para a vida adulta, o sentido das suas ações no presente. Sob essa perspectiva, há uma tendência de encarar a juventude na sua negatividade, o que ainda não chegou a ser (Salem, 1986), negando o presente vivido. Essa concepção está muito presente na escola: em nome do 'vir a ser' do aluno, traduzido no diploma e nos possíveis projetos de futuro, tende-se a negar o presente vivido do jovem como espaço válido de formação, assim como as questões existenciais que eles expõem, bem mais amplas do que apenas o futuro. (DAYRELL, 2003, p. 40-41).

Corroborando com o apontado pelo autor, chegamos à conclusão de que não dá para se pensar a juventude, principalmente os que estão presentes nos territórios rurais ou no campo, como os narradores desta pesquisa sinalizam, como mero recorte temporal ou como prognóstico para o futuro. Passam a viver o tempo atual e suas nuances formativas como possibilidades de autoafirmação e reconhecimento, são sujeitos sociais e o transitório aqui é apenas demarcado como o corte no tempo em que saem de sua zona de conforto e migram para outros espaços em busca de crescimento e conhecimento, neste caso de formação profissional, mas que não define ali os aspectos inerentes ao seu futuro ou a denominação enquanto sujeitos.

Os jovens passam a se reconhecer como sujeitos e que desta maneira são dotados de projetos e planos para o futuro e, mediados por este movimento transitório, temporário em que demarcam sua condição juvenil, não como o reflexo de um futuro próximo. Vejamos o que diz esta jovem, "[...] hoje eu penso diferente, quero terminar o curso técnico e fazer faculdade em zootecnia e dar um futuro diferente a minha comunidade, [...] aquela carcará que chegou aqui antes, não existe mais [...]" (Carcará, diário do cotidiano, 2018).

Diante do exposto, acreditamos que com todos os elementos aqui explicitado, especificamente relacionada a estes jovens que são de origens diferentes, seja do campo com bases tradicionais (indígenas, quilombolas, pescadores, agricultores familiares, familiares, fundo de pasto, movimentos sociais, etc.), se constituem como jovens transitórios, sendo o resultado do processo de construção do sujeito, a partir do hibridismo juvenil, influenciado pelos movimentos transitórios, o que configura como principal desafio para se pensar e propor processos formativos que atendam às necessidades específicas destes sujeitos, seja no campo educacional, de movimentos sociais e/ ou da ecologia humana, como propomos articular ao longo do artigo.

\section{Referências}

BARDIN, Lauris. Análise de conteúdo. São Paulo: Edições 70, 2011.

BERNIERI, Mailor José. Diversificação de actividades no espaço rural: turismo, mais um componente para o desenvolvimento local? 2002. Dissertação (Mestrado) - Universidade de Trás-os-Montes e Alto Douro, Vila Real/Universidade de Santiago de Compostela, Santiago de Compostela, 2002.

BRASIL. Estatuto da juventude: atos internacionais e normas correlatas. Brasília, DF: Senado Federal/Coordenação de Edições Técnicas, 2013.

CACCIA-BAVA, Silvio. Tecnologia social e desenvolvimento local. In: FUNDAÇÃO BANCO DO BRASIL (org.). Tecnologia social: uma estratégia para o desenvolvimento. Rio de Janeiro: FBB, 2004. p. 103-116.

CARNEIRO, Maria José Teixeira. O ideal urbano: campo e cidade no imaginário de jovens rurais. In: SILVA, Francisco Carlos Teixeira; SANTOS, Raimundo; COSTA, Luiz Flávio Carvalho. Mundo rural e política: ensaios interdisciplinares. Rio de Janeiro: Mauad, 1998. 
CARVALHO, Luzineide Dourado. Natureza, território e desenvolvimento rural no semiárido brasileiro: estudo preliminar as ações da "convivência com o semi-árido" em Juazeiro-Bahia. In: ENCONTRO DA REDE DE ESTUDOS RURAIS, 3., 2008, Campina Grande. Anais [...]. Campina Grande: UFCG, 2008.

CHAVES JÚNIOR, Elizeu de Oliveira. Políticas de juventude: evolução histórica e definição. In: SCHOR, Néia; MOTA, Maria do Socorro Tabosa; BRANCO, Viviane Castello (org.). Cadernos de juventude, saúde e desenvolvimento. Brasília, DF: Ministério da Saúde/Secretaria de Políticas de Saúde, 1999. p. 41-48.

CLÍMACO, Adélia Araújo de Souza. Repensando as concepções de adolescência. 1991. Tese (Mestrado em Psicologia) - Pontifícia Universidade Católica de São Paulo, São Paulo, 1991.

COSTA, Simone Gomes. A equidade na educação superior: uma análise das Políticas de Assistência Estudantil. 2010. Dissertação (Mestrado em Sociologia) - Universidade Federal do Rio Grande do Sul, Porto Alegre, 2010.

COSTA, Tiago Pereira da. A convivência com o semiárido como paradigma sustentável na perspectiva do bem viver. REVASF, Petrolina, v. 7, n. 12, p. 79-100, abr. 2017.

DAYRELL, Juarez. O jovem como sujeito social. Revista Brasileira de Educação, Rio de Janeiro, n. 24, p. 40-52, set./out./dez. 2003.

DICK, Hilário. Gritos silenciados, mas evidentes - jovens construindo juventude na História. São Paulo: Edições Loyola, 2003.

GROPPO, Luís Antônio. Juventude: ensaios sobre sociologia e história das juventudes modernas. Rio de Janeiro: DIFEL, 2000. Coleção Enfoques Sociologia.

GUDYNAS, Eduardo. Transições ao pós-extrativismo: sentidos, opções e âmbitos. In: DILGER, Gerhard; LANG, Miriam; PEREIRA FILHO, Jorge (org.). Descolonizar o imaginário: debates sobre pós-extrativismo e alternativas ao desenvolvimento. São Paulo: Fundação Rosa Luxemburgo, 2016. p. 174-212.

IMPERATOR, Thaís Kristosch. A trajetória da assistência estudantil na educação superior brasileira. Serviço Social e Sociedade, São Paulo, n. 129, p. 285-303, maio/ago. 2017.

LAFER, Celso. O significado de República. Rev. Estudos Históricos, Rio de Janeiro, v. 2, n. 4, p. 215-224, 1989.

MACHADO, Otávio Luiz. As repúblicas estudantis. In: LEMOS, Paulo. A história da Escola de Minas. Ouro Preto: Legraphar, 2013a. p. 176-182.

MACHADO, Otávio Luiz. Escola de Minas de Ouro Preto: memórias dos seus ex-alunos. Frutal: Editora Prospectiva, 2013b. MACHADO, Otávio Luiz. República Aquarius: a maior república estudantil das Américas. Frutal: Editora Prospectiva, 2013c.

MALTA, Eder. Identidade e práticas culturais juvenis: as repúblicas estudantis de Ouro Preto. 2010. Dissertação (Mestrado em Ciências Sociais) - Universidade Federal de Sergipe, São Cristóvão, 2010.

MARCHELLO-NIZIA, Christiane. Cavalaria e cortesia. In: LEVI, Giovanni; SCHIMITT, Jean-Claude (org.). História dos Jovens 1: da antiguidade à era moderna. São Paulo: Companhia das Letras, 1996. p. 141-190.

MENDÉS-FRANCE, Pierre. A República Moderna. Lisboa: Europa-América, 1963.

NIETZSCHE, Friedrich. A Gaia ciência. Tradução, notas e posfácio de Paulo Cezar de Souza. São Paulo: Companhia das Letras, 2001.

NOVAES, Regina. Juventude e participação social: apontamentos sobre a reinvenção da política. In: ABRAMO, Helena Wendel et al. (org.). Juventude em debate. São Paulo: Cortez, 2000.

OLIVEIRA, Adelson Dias de. Jovens no Semiárido baiano: experiências de vida e formação no campo. 2014. Dissertação (Mestrado em Educação) - Programa de Pós-Graduação em Educação e Contemporaneidade, Faculdade de Educação, Universidade do Estado da Bahia, Salvador, 2014.

OLIVEIRA, Lucia Marisy Souza Ribeiro de. EDUCAÇÃO RURAL E DESENVOLVIMENTO LOCAL SUSTENTÁVEL: A Lógica Subjacente das Relações Inter-Setoriais. BELÉM-PA. 2005.

OUA (Organização da Unidade Africana). Análise situacional da juventude em África. In: CONFERÊNCIA PAN AFRICANA SOBRE JUVENTUDE E DESENVOLVIMENTO, 1996, Etiópia. Anais [...]. Etiópia: Comissão Econômica para a África, 1996.

PAIS, José Machado. Culturas juvenis. Lisboa: Imprensa Nacional/Casa da Moeda, 2003.

REIS, Nestor Goulart. Notas sobre urbanização dispersa e novas formas de tecido urbano. São Paulo. Via das Artes, 2006. 
REPOLÊS, Maria Fernanda Salcedo. A identidade do sujeito constitucional no Brasil - uma visita aos seus pressupostos histórico-teoréticos na passagem do Império para a República, da perspectiva da forma de atuação do guardião máximo da Constituição. In: ENCONTRO PREPARATÓRIO DO CONPEDI, 16., 2007, Campos dos Goytacazes. Anais [...]. Campos dos Goytacazes: Conpedi, 2007.

SCHNAPP, Alain. A imagem dos jovens na cidade grega. In: LEVI, Giovanni; SCHIMITT, Jean-Claude (org.). História dos Jovens 1: da antiguidade à era moderna. São Paulo: Companhia das Letras, 1996. p. 19-57.

SILVA, Vanda. Sertão de jovens: antropologia e educação. São Paulo: Editora Cortez, 2004.

SOUSA, Janice Tirelli Ponte de. Reinvenções da utopia: a militância política de jovens dos anos 90. São Paulo: Editora Hacker, 1999.

Data de submissão: 31/01/2021

Data de aceite: 18/02/2021 